\section{Intravascular approach to the treatment of cerebral arteriovenous malformations and dural arteriovenous fistulae}

\section{Pieter Fourie MBChB(Pret), MMed(Rad)Pret \\ Consultant Radiologist Pretoria Heart Hospital}

\section{Treatment} options for AVMs and fistulae are explored and results are presented from this South African centre.

\section{Introduction}

Cerebral arteriovenous malformations (AVMs) may pose as one of the more formidable challenges to a neurosurgeon. ${ }^{1}$

A multi-disciplinary approach includneuroradiologists and radiosurgeon and neurologists, seems to be the ideal modern day treatment of these lesions.

Complications due to AVMs include haemorrhage, mass effects, epilepsy and bruit.

\section{Diagnosis}

With the advent of computed tomography (CT) andmagnetic resonanceimaging(MRI) as well as three dimensional MRI and spiral $\mathrm{CT}$, the anatomical information such asnidus size, functional location and venous drainage and surrounding state of the brain can becomereadily known(Figure 1). ing the neurosurgeon, interventional

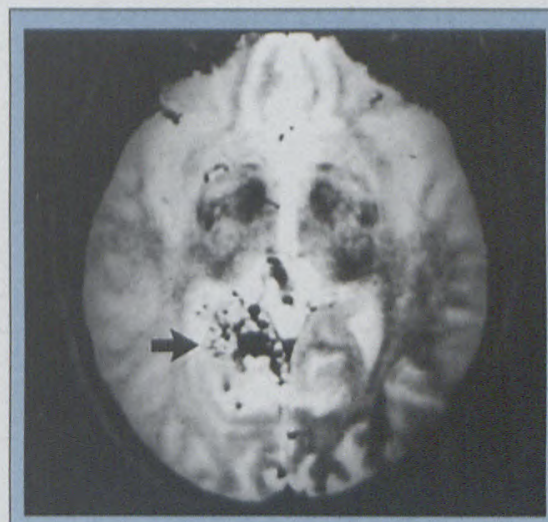

Figure 1:Magnetic resonance imaging can be used as a useful tool in the diagnostic approach to AVMs. The anatomical location, size, venous drainage and condition of the surrounding brain can be demonstrated. (Arrow)

The gold standard as a diagnostic tool is however angiography. Digital subtraction angiography is of great value especially when one of the newer generation X-ray machines is used with a high pixel rating, magnification and good road mapping abilities. (Figures $2 \mathrm{a} \& \mathrm{~b}$ )

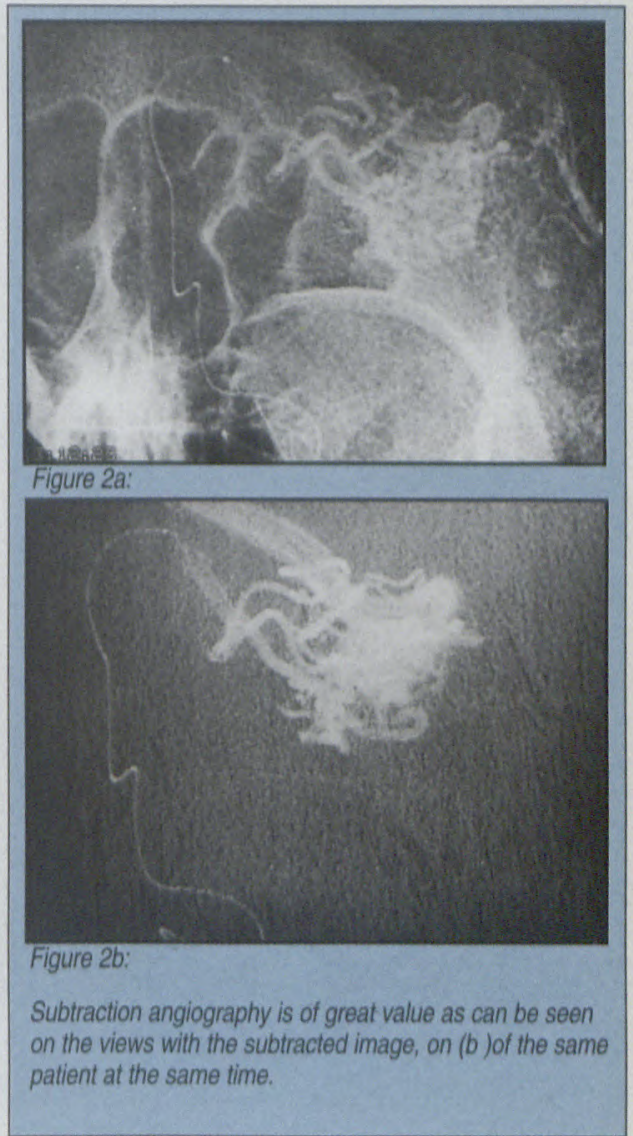


from page 17

\section{History and development}

The intravascular treatment of AVMs has its origin with Zuessen-hop et al. ${ }^{2}$ They used silastic spheres injected via a direct surgical approach in the internal carotid and vertebral arteries. The spheres were then flow directed to the lesion. It was however non-selective and occluded mostly the proximal feeding vessels. The nidus often recanalised through leptomeningeal, transmedullary and transdural collateral vessels. It was of little value where small arteries supplied the lesion e.g. perforating arteries.

Serbinenko ${ }^{3}$ in 1974 described safe selective intracranial catheterisation beyond the circle of Willis, using detachable balloons to occlude the larger feeding arteries of theAVMs and fistulae. The use of a calibrated leak balloon on a micro-catheter was reported by Kerber in 1976. Distal navigation became possible and the use of acrylic agents was introduced for the occlusion of the nidus. These catheters needed to be inflated for the advance into the arterial system butcaused complications likerupture and haemorrhage ${ }^{5}$ Only fluids could be injected through it precluding the use of particles, because of its small lumen diameter.

During 1988-89 new micro-catheters were developed that made super selective catheterization deep into the distal arterial tree possible. The new over the wire

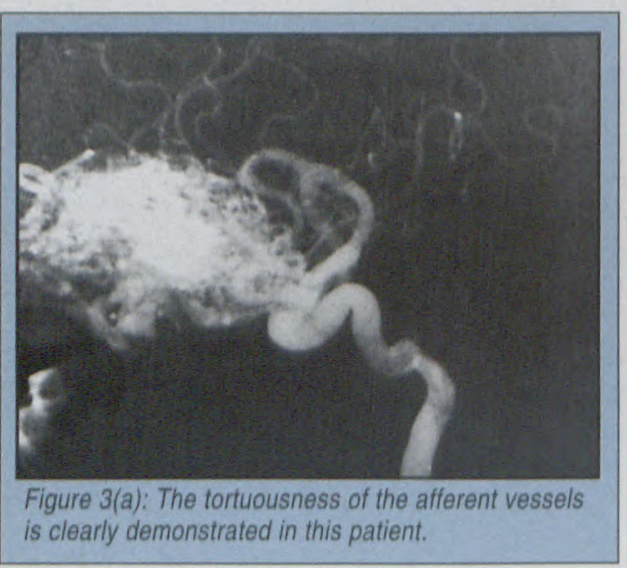

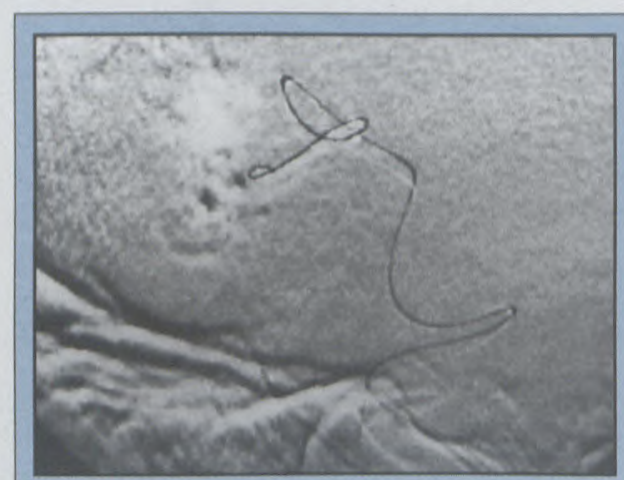

Figure 3(b): The catheter on the right has to follow suit to the nidus.

catheters made it possible to introduce a wide variety of particles into the nidus and supplying pedicles(Figures $3 \mathrm{a} \& \mathrm{~b}$ ). The flow-guided catheters allowed only fluids and very small particles, but could be negotiated into very small tortuous and distal vessels.

\section{Anatomy of AVMs}

A cerebral AVM usually consists of a nidus or central part, supplied by arterial feeders and draining vein or veins (Figures $4 a \& b$ ).

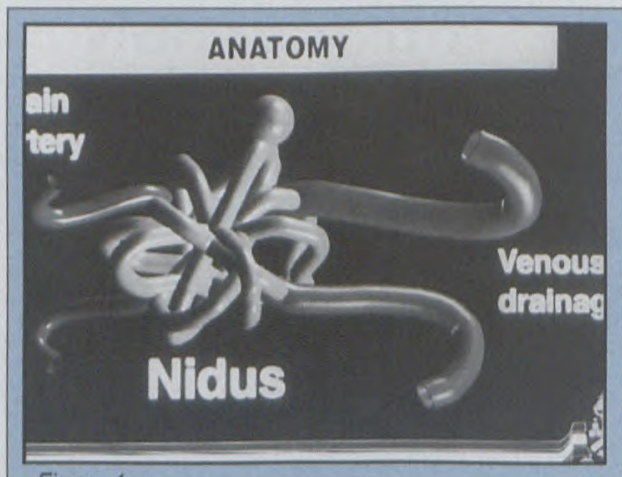

Figure 4a:

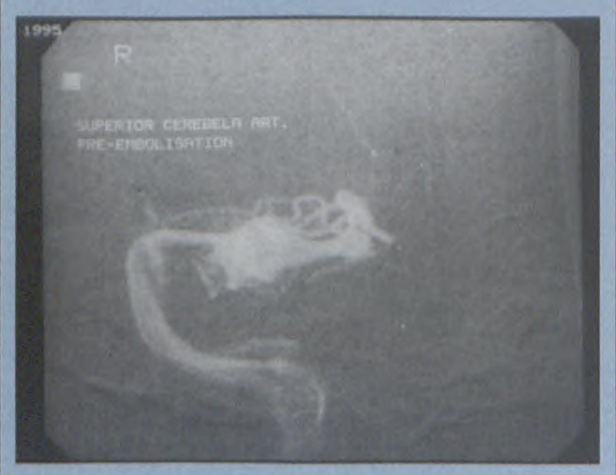

Figure 4b:The nidus, arterial supply and venous drainage are seen (a) in this model and demonstrated (b) in a patient.
Each nidus is composed of a series of compartments which could be in contact with one another. The compartments are fed by different arterial pedicles. Because of the high flow (from 150-900 $\mathrm{ml} / \mathrm{min}$ with an average of $490 \mathrm{ml} / \mathrm{min})^{6}$ these pedicles are quite large. According to the Hagen-Poiseville equation the flow in the feeding artery is directly related to the feeding artery's blood pressure and the fourth power of its radius. It is inversely related to thelength of the pedicle.

$$
\mathrm{Q}=\frac{\Delta \mathrm{P} \times \pi \mathrm{r}^{4}}{8 \times \mathrm{L} \times \eta}
$$

$\eta$ is the viscosity of the blood.

$\mathrm{P}$ is the intraluminal pressure

$\mathrm{L}$ is the length of the vessel

It is generally accepted that large AVMs with high flow usually have a low arterial pressure and less chance of haemorrhage than the smaller slow flow but high pressure lesions. The larger lesions present more often with seizures. ${ }^{7}$ Miyasaka et al $l^{8}$ concluded that fewer draining veins increased the risk of haemorrhage.

During embolisation intra-arterial pressure would rise significantly. ${ }^{9}$ It is also clear that the intraluminal pressure of the feeding arteries is much less than that of the carotid or vertebral arteries in the neck. ${ }^{10}$ Gradients of up to $75 \mathrm{~mm} \mathrm{Hg} \mathrm{have}$ been reported. This gradient however subsides after nidal embolisation.

The high flow state in the feeders, nidus and draining veins causes histological changes that enhance the preponderance of local trauma during catheterisation and manipulation. ${ }^{11}$

\section{Grading of AVMs}

The surgical grading system devised by Spetzler and Maartin ${ }^{12}$ correlates the risk following surgical removal of AVMs. We find it an excellent way of entrée to the 


\section{from page 18}

treatment of these lesions. Where embolisation is concerned the difficulty in approaching the lesions via the intraluminal paths, the tortuousness and length and number of vessels, as well as the presence of large fistulae in the nidus play important roles concerning the outcome of the procedure and should be taken into account.

\section{Embolic agents}

The ideal material for endovascular embolization of AVMs hasyet to be discovered. Ideally, an embolic agent should be non-biodegradable, non-toxic, and nonmutagenic. It should be easily delivered through a microcatheter, be easily seen on fluoroscopy, and adhere to the walls of the vessels without extravasation or recanalization. Finally, the ideal embolic material should be soft enough to allow retraction of the lesion from surrounding normal tissues during surgical excision.

Many different embolic agents were used like silk, coils, microspheres (metal, polyvinyl alcohol, Spongistan) and liquid adhesive polymers.

Of the liquid adhesive polymers, alkyl cyanoacrylate monomers have been most widely used. Two kinds are used these days viz. isobutyl 2-cyanoacrylate (IBCA) and n-Butyl cyanoacrylate (NBCA). Once the monomer is exposed to an ionic fluid (like blood) it polymerizes immediately. A tight bond between tissue and the polymer exists that is used to bond tissues together in surgery ${ }^{13}$ (Figure5).

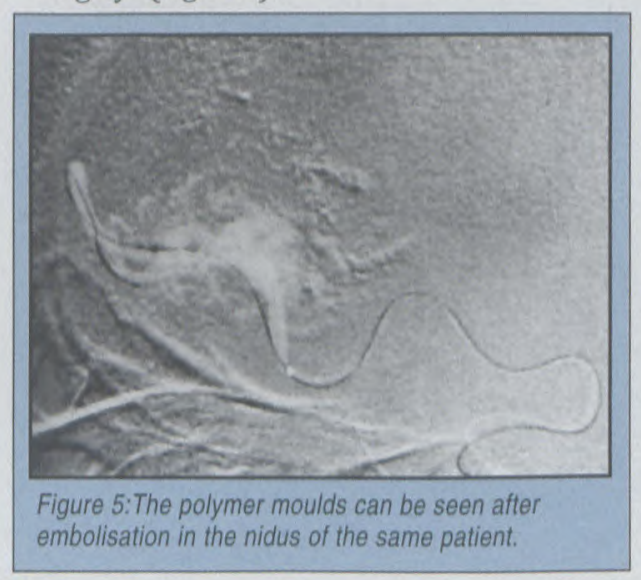

Vinters et al reported on the long term follow-up of cerebral AVMs treated by embolization with bucrylate. ${ }^{14}$ They found bucrylate in the extra-vascular space 41 days after embolization and occasionally earlier. Although the nidus can be fully embolised with these materials, re-canalization does occur up to 12-20 monthslater. ${ }^{15}$

It is a good embolic agent, but by no means permanent. IBCA is quite brittle and therefore difficult to handle at surgery, without traumatizing the brain. Carcinogenicity is also a concern. IBCA has been replaced by n-Butyl cyanoacrylate. ${ }^{16}$ Bucrylates have been used for the treatment of AVMs for the last 15 years without any report in the literature of the proposed mutagenicity having occurred. ${ }^{17}$ However, NBCA is less brittle than IBCA and has a slightly shorter polymerization time.

Other liquids in the offing are ethylene vinyl alcohol copolymer introduced by Taki et al ${ }^{18}$ and estrogon alcohol and polyvinyl acetate $^{19}$

Patho-histological changes after embolization with polymers include a foreign body response followed by an inflammatory response $\mathrm{e}^{20}$ and vessel wall necrosis followed by either aneurysms and/or extra-vascular appearance of the polymer. Haemorrhage may occur due to the secondary formed aneurysms after embolisation.

Haemorrhage associated with AVM embolisation ranges from $3-11 \%{ }^{21}$ We administer Nimodipine and steroids intravenously during and after the procedure. Nimodipine is usually administered before the procedure.

\section{Particulate materials}

The most commonly used particulate is polyvinyl alcohol. Sizes from 75 to $1250 \mu \mathrm{m}$ are available. The particles are suspended in diluted contrast and injected at small non-laminar flow boluses. Starting from the smaller particles enhances the possible blocking of the smaller intra-nidal vessels followed by thelarger ones to occludelarger vessels and fistulae. The main pedicle can be occluded with silk or fibred coils. When fistulae are present pulmonary embolism may occur.

It is reported that collagen (avitene) may enhance the thrombo-genecity of the mixture $^{22}$

Tissue response to PVA is well described by Germano et $a^{23}$ in the brain. They investigated 66 consecutive excised AVMs histologically, that were embolised with PVA before surgery. They found an inflammatory response in the vessels, including angionecrosis of the wall, even as soon as two weeks post-procedurally. Foreign material was found in $63 \%$ of cases. Recanalization occurred in $18 \%$ of lesions within four weeks.

Pulmonary embolism during the treatment is a well known complication. Venous outlet obstruction can pose a high risk if the inflow to the AVM is still prevalent and extremely high. ${ }^{24}$

\section{Technique}

Grading according to Spetzler and Maartin is done on MR or CT, followed by an angiogram for further assessment of velocity, pedicle, nidus size and appearance, draining veins and anterior and/or posterior cerebral supply.

The clinical judgement for possibleway of treatment resides mostly with the referring neurosurgeon.

In some centres general anaesthesia is administered and in others neurolept analgesia. Purdy et al ${ }^{5}$ say that unless the feeding pedicle is fully embolised sodium Amytal testing is not needed.

Nowadays we tend to embolise our patients while they are awake and resort to provocativetesting.

Our patients are heparinised $(5000$ units) where the pedicles are not easily 


\section{Intravascular approach to the treatment of cerebral AVMs and dural arteriovenous}

fistulae

\section{from page 19}

negotiable. We prefer not to use heparin when the lesion is easily approachable and where arterial spasm of pedicles is less of a problem. Once the patient is heparinised we prefer not to administer protamine sulphate but allow the activated clotting time (ACT) to come down to 150 seconds before we remove the sheath from the femoral artery.

All our patients are placed in the intensive care unit for a 24-48 hour observation period after treatment. They are discharged as soon as their condition allows it.

\section{Provocative testing}

The so-called Wada Test was first done by Wada and Rasmussen. ${ }^{26}$ They injected sodium amobarbital (Amytal) within the internal carotid artery (ICA) to evaluate cerebral dominance before epilepsy surgery. When Amytal is injected into a feeding pedicle of an AVM reversible changes to normal brain can be elicited according to Ranch et al. ${ }^{27}$

We now administer $\pm 35 \mathrm{mg}$ Amytal before embolisation in two distinct boluses. The first bolus is given slowly to flush the normal distal brain. The second bolus is given as fast as possible to cause, if possible, slight retrograde reflux into the feeding pedicle. Once polymer is injected the flow state of the AVM changes and may cause stasis of blood flow with possible untoward embolisation of the pedicle. Immediately after the administration of the Amytal a neurologist in theatre tests areas of eloquence close to the lesion. When a negative response is elicited embolisation is commenced. Brevital may also be used. ${ }^{28}$ It has a shorter half life than Amytal and is more readily available in South Africa(Figure 6).

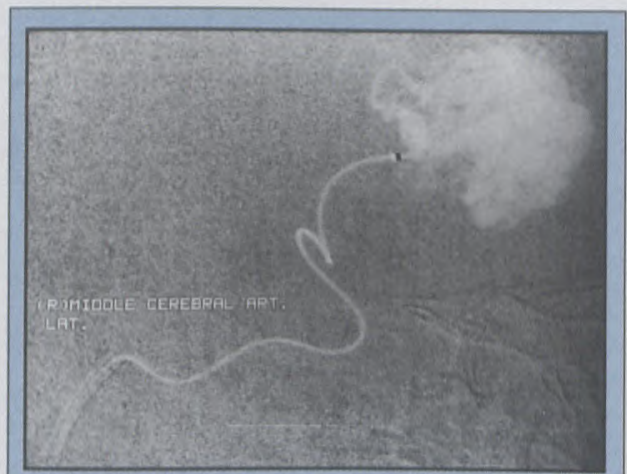

Figure 6: The catheter tip should be as close as possible to the nidus before provocative testing is done and treatment commenced.

Ten therapeutic options exist for AVMs:

1 Notherapy

2 Microsurgery

3 Radiosurgery

4. Embolisation

5 Embolisation plus microsurgery

6. Embolisation plus radiotherapy

7. Staged surgical procedure

8 Conventional surgery followed by radiosurgery

9. Radiosurgery followed by conventional surgery

10. Various triple therapy combinations ${ }^{29}$

\section{Clinical materials and methods}

Between April 1995 and May 199613 patients with AVMs were treated in our unit by means of the endovascular route.

The indications for treatment were:

Palliation in non-resectableAVMs.

Pre-surgical devascularization.

Diminution of nidus size in com-

bination with radiosurgery.

Total obliteration.

Two patients were treated with PVA as a presurgical adjunct. The rest of the cases were embolised with polymer, of which two wereoperated on later. Twelvepatients were male and $\mathrm{l}$ female. Their ages varied from 19 to 53 with the average age of 37.3 years. Seven cases were graded as Hunt \& Hess I and four cases as Hunt and Hess II and two as Hunt and Hess III. The first two cases were done under general anaesthesia and last 11 under local anaesthetics.

Four patients' AVMs were graded as Spetzler and Maartin GradeIV and the rest as Grade II and I. The last 11 patients were subjected to sodium Amytal provocative testing. Staged procedures were done in threepatients.

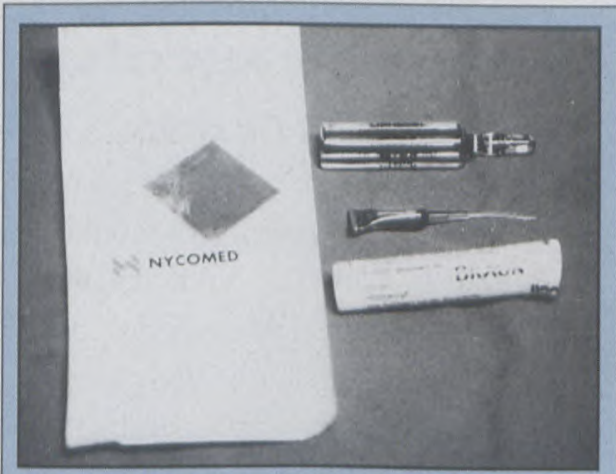

Figure 7:From top to bottom, Lipiodol in a glass vial, then the polymer in a small plastic vial. Tungsten powder is supplied in sterile plastic sachets.

We use a mixture of Lipiodol, Tungsten powder andNBCA (Figure 7). Thefaster the flow, the faster polymerization isneeded and the less Lipiodol is added and vice visa. The idea is to completely fill the nidus with the polymer without venous occlusion.

\section{Results}

All patients has a diminution in size of the AVMs(Figures $8 \mathrm{a} \& \mathrm{~b}$ ).

All the presurgical patients were successfully operated on, one of which was followed up and showed no recurrence. The others are due for follow-up MRI and angiography.

One patient was completely cured on the one year follow-up angiogram.

One epileptic patient has had no seizures since the procedure but remains on anti-epileptic treatment.

Onepatient with a massive frontalAVM had a personality change for the better.

\section{Complications}

Two patients with lesions in their dominant hemispheres had temporary speech deficits post procedure. 


\section{Intravascular approach to the treatment of cerebral AVMs and dural arteriovenous fistulae}

\section{from page 20}

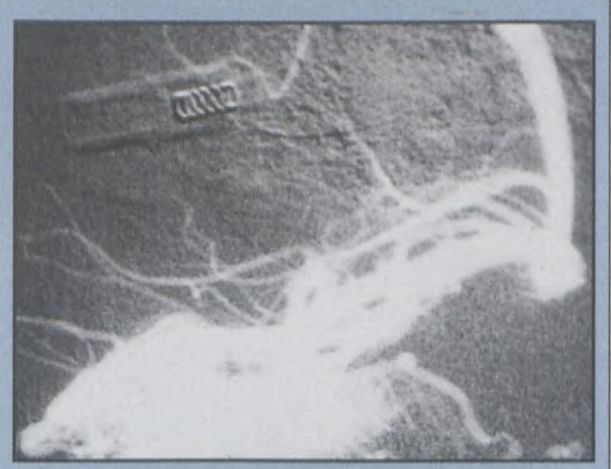

Figure 8a

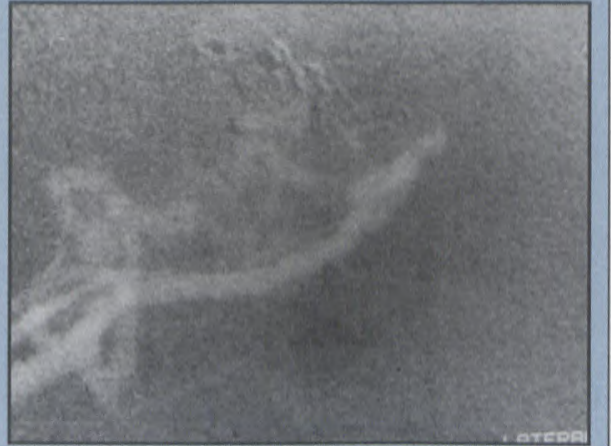

Figure $8 b$

Angiographic appearance (a) before and (b) after embolization of this posterior cerebral artery AVM.

One had a writing deficit that resolved after a few weeks.

One patient developed slow retrograde thrombosis of the calloso-marginal artery and subsequently developed hemiplegia.

No deaths occurred and no haemorrhages occurred.
One patient developed severe vascular spasm causing us to terminate the initial procedure. The endovascular therapy for vasospasm due to haemorrhage or catheter manipulation includes papaverine hydrochloride. Up to 300mg can be infused at a time over a period of one hour. ${ }^{30}$

Pre-surgical embolisation was achieved step by step using PVA until the proper results hadbeen achieved. These patients were operated on 48-72 hours later (Figure 9).

Amixture of polymer and PVA can be helpful with the latter occluding small or evenlargerparts of the residual lesion after initial embolisation with polymer(Figure. 10).

Radiosurgery with the gamma knife or other modes of radiation can be important adjuncts to the treatment of theselesions, but is beyond the scope of this article.

Three of these patients had dural arteriovenous fistulas which were treated with polymer. In the follow-up angiograms

\begin{tabular}{|c|c|c|c|c|c|c|c|c|}
\hline Patient & 0'lo & Age & $H \& H$ & Place & Glue & PVA & Results & $\%$ \\
\hline 1. $B$ & ó & 28 & 1 & Mid \& ant cerebral art & + & & Temporary writing \& speech & 95 \\
\hline 2. $D$ & o' & 43 & 11 & Post cerebral & + & & No deficit & 70 \\
\hline 3. $P$ & 우 & 19 & 111 & Superior cerebral & + & & Slight & 95 \\
\hline 4. $M$ & ơ & 42 & 1 & Mild, post external carotis & + & & No deficit & 90 \\
\hline 5. $S$ & ơ & 38 & 11 & Middle cerebral & + & & No deficit & 95 \\
\hline 6. $\mathrm{K}$ & $\sigma^{\prime}$ & 43 & 11 & Post cerebral & + & & No deficit & 80 \\
\hline 7. $\mathrm{N}$ & $\sigma$ & 41 & 1 & Dural \& external carotis & + & & No deficit & 90 \\
\hline 8. B & $\sigma$ & 31 & 111 & Anterior cerebral & + & & Hemiplegia & 90 \\
\hline 9. $\mathrm{D}$ & $\sigma$ & 42 & 1 & Anterior cerebral & + & & No deficit & 90 \\
\hline 10. $\mathrm{G}$ & $\sigma$ & 32 & 1 & Ext carotid vertebralis & 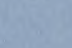 & + & No deficit & 90 \\
\hline 11. V & o' & 29 & & Middle cerebral & + & & No deficit & 80 \\
\hline 12. $M$ & o" & 53 & 11 & Middle cerebral & + & & Slight speech deficit & 90 \\
\hline 13. $S$ & o & 44 & 1 & Middle cerebral & & + & No deficit & 95 \\
\hline
\end{tabular}

Figure 9: Patients treated with AVMs and dural fistulae with ages, gender and Hunt \& Hess (H\&H) grading tabulated. Outcomes are demostrated on the right. two of these patients had recurrence of different arteries supplying the fistulae. It is now a known fact that these lesions are acquired usually secondary to venous thrombosis $^{31}$ or hypertension ${ }^{32}$. In many cases the pathogenesis is unknown. Normal microarteriovenous shunts exist between the arterial and venous systems. Due to abnormal pressures in the venous side caused by

Figure 10:The histological response to these two agents in the use of AVM reatment is compared.

\section{IBCA vs PVA}

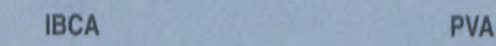

1. More inflammatory response

2. Extra vasation

3. Pulmonary embolisation

4. Recanalization little

5. Less collaterals

Mutaganicity Ames test + NBVA IBCA not proven. (Berenstein A et al, J Neurosurg, 67:318-319,1987

Comparison: Valavanis uses both
Less inflammatory response No or very little extravasation Pulmonary embolisation Recanalization $18-30 \%$ New collaterals form rapidly when totally occluded

Ames test- but Oppenheimer BS showed + mutagenicity (Cancer Res 15:333-340,1955) 


\section{from page 21}

techniques. Close cooperation between all the clinicians involved is essential.

\section{Conclusion}

The endovascular approach to the treatment of arteriovenous malformations of the brain and dural arteriovenous fistulae is an adjunct to surgery and radiation therapy in these very important conditions. Close cooperation between the specialistsinvolved is of utmost importance. The therapeutic vision should be that of total therapy using a multi-disciplinary approach.

\section{References}

1.Wilson CB, UHS, Doninque J: Microsurgical treatment of intracranial vascular malformations. JNeurosurg 1979;51:446-454.

2.Luessenhop AJ, Spence WT: Artificial embolization of cerebral arteries. Report of use in a case of arteriovenous malformation. JAMA 1960;172:1153-1155.

3.Serbinenko FA: Balloon catheterization and occlusion of major cerebral vessels. JNeurosurg 1974;41:125-145.

4.Kerber C: Balloon catheter with a calibrated leak. A new system for superselective angiography and occlusive catheter therapy. Radiology 1976;120:547-550.

5.Viñuela F, Fox AJ, Pelz D, et al: Stenotic and occlusive disease of the venous drainage system of deep brain AVMs. JNeunosung 1985;63:180-184.

6.Nornes H, Grip A: Hemodynamic aspects of cerebral arteriovenous malformations. J Neurosurg 1980;53:456464.

7. Spetzler RF, Hargraves RW, McCormick PW, et al: Relationship of perfusion pressure and size of risk of hemorrhage from arteriovenous malformations. $J$ Neurosung 1992;76:918-923.

8.Miyasaka Y, Yada K, Kurata A, et al: Correlation between intravascular pressure and risk of hemorrhage due to arteriovenous malformations. Surg Neurol $1993 ; 39: 370-373$

9.Jungreis CA, Horton JA: Pressure changes in the arterial feeder to a cerebral AVM as a guide to monitoring therapeutic embolization. AJNR 1989;10:1057-1060.

10.Duckwiler GR, Dion JE, Viñuela F, et al: Intravascular microcatheter pressure monitoring: experimental results and early clinical evaluation AJNR 1990;11:169-175.

11.Pile Spellman JMD, Baker KF, Liszczak TM: Highflow angiopathy: cerebral blood vessel changes in experimental chronic arteriovenous fistula. $A J N R$ 1986,7:811-815.

12.Spetzler RF, Martin NA: A proposed grading system for arteriovenous malformations. J Neurosurg 1986;65:476-483.

13. Brothers MF, Faufmann JCE, Fox AJ, et al: N-butyl2-cyanoacrylate - substitute for IBCA in interventional neuroradiology: histopathologic and polymerization time studies. AJNR 1989;10:777-786,
14. Halbach VV, Higashida RT, Hieshima GB, et al: Normal perfusion pressure breakthrough occurring during treatment of carotid and vertebral fistulas. AJNR 19889:741-747.

15.Rao VRK, Mandalam KR, Gupta AK, et al: Dissolution of isobutyl 2-cyanoacrylate on long-term followup. ANNR 1989;10:135-141

16.Jafar JJ, Davis AJ, Berenstein A, et al: The effect of embolization with $\mathrm{N}$-butyl cyanoacrylate prior to surgical resection of cerebral arteriovenous malformations. INeurosurg 1993;78:60-69.

17. Nelson RE, Stears JG, Barnes GT, et al: Acceptance testing of radiologic systems: experience in testing 129 imaging systems at two major medical facilities. Radi ology 1992;183:563-567.

18.Taki W, Yonekawa Y, Iwata $\mathrm{H}$, et al: A new liquid material for embolization of arteriovenous malformations. AJNR 1990;11:163-168.

19.Su CC TakahashiA Yoshimoto T et al:Histo-pathological studies of a new liquid embolization method using estrogen-alcohol and polyvinyl acetate. Experimental evaluations with a model of cortical arterial cannulation in the caninebrain. SungNeurol 1991;36:4-11.

20.Viners HV, Debrun G, Kaufmann JCE, et al: Pathology of arteriovenous malformations embolized with isobutyl-2-cyanoacrylate (bucrylate). Report of two cases, JNeurosurg 1981;55:819-825.

21.Purdy PD, Batjer HH, Samson D: Management of hemorrhagic complication from preoperative embolization of arteriovenous malformations. $J$ Neumosurg 1991;74:205-211

22. Lee DH, Wriedt $\mathrm{CH}$, Kaufmann JCE, et al: Evaluation of three embolic agents in pig rete. AJNR 1989:10:773-776.

23. Isabelle M, Germano, MD., Richard L Davis MD et al: Histopathological follow-up study of 66 cerebral arteriovenous malformation after therapeutic embolization with polyvinyl alcohol. JNeurosurg 1992;76:607-614

24.Duckwiler GR, Dion JE, Viñuela F, et al: Delayed venous occlusion following embolotherapy of vascular malformations in the brain. AJNR 1992;13:1571-1579.

25. Purdy PD, Batjer HH Risser RC, etal: Arteriovenous malformations of the brain: choosing embolic materials to enhance safety and ease of excision. JNeurosurg 1992;77:217-222

26.Wada J, Rasmussen T: Intracarotid injection of sodium Amytal for the lateralization of cerebral speech dominance. JNeurosurg 1960;17:266-282.

27. Rauch RA, Viñuela F, Dion J, et al: Pre-embolization functional evaluation in brain arteriovenous malformations: the ability of superselective Amytal test to predict neurologic dysfunction before embolization. AJNR 1992;13:309-314.

28.Peters KR, Quisling RG, Gilmore R, et al: Intra-arterial use of sodium methohexital for provocative testingduring brain embolotherapy. AJNR 1993;14:171-174.

29. Robert C Dawson MD, David S Owens et al: A multidisciplinary approach to recalcitrant arteriovenous malformations of the brain. Endovascular Neurological Intervention, 1995;page 203.

30.Kassel NF, Helm G, Simmons N, et al: Treatment of cerebral vasospasm with intra-arterial papaverine. $J$ Neumosurg 1992;77:848-852
31. Houser OW, Campbell JK, Campbell RJ, et al: Arteriovenous malformation affecting the transverse dural sinus - an acquired lesion. Mayo Clin Proc 1979,54:651-661.

32.Terada T, Higashida R, Halbach VV, et al: Development of acquired arteriovenous fistulas in rats due to venous hypertension. JNeurosurg 1994;80:884-889.

33.Djindjian R Cophignon J, Théron J: Embolization by superselective arteriography from the femoral route in neuroradiology. 1. Review of 60 cases. Technique, indications, complications. Neuroradiology 1993;6:2026 .

34.Lalwani AK, Dowd CF, Halbach VV: Grading venous restrictive disease in patients with dural arteriovenous fistulas of the transverse/sigmoid sinus. JNeurosurg 1993;79:11-15.

35.Van V Halbach MD, Randall THigashida, MD. et al: Treatment of Dural Arteriovenous Fistulas. Endovascular Neurological Intervention, page 1995;217. 246.

\section{Note to Contributors}

The Conditions of Submission and Instructions to Authors are available on request from:

ThePublisher,

Cannon Medical Media (Pty) Ltd, POBox2433, Randburg, 2125, South Africa. 